\title{
Young onset fronto-temporal dementia - A case report
}

\author{
Parijat Roy ${ }^{1}$, Prashant Chaudhari ${ }^{2}$, Heena Merchant-Pandit ${ }^{3}$, Nilesh $\mathrm{Shah}^{4}$ Sagar Karia $^{5}$, Avinash De Sousa ${ }^{6 *}$ \\ ${ }^{1,2}$ Resident Doctor, ${ }^{3}$ Associate Professor, ${ }^{4}$ Professor and Head, ${ }^{5}$ Assistant Professor, ${ }^{6}$ Research Associate, Dept. of Psychiatry, Lokmanya
} Tilak Municipal Medical College, Mumbai, Maharashtra, India

*Corresponding Author: Avinash De Sousa

Email: avinashdes888@gmail.com

\begin{abstract}
Dementia as a diagnosis at any age is a clinical challenge in psychiatric practice. In recent research reports there have been many case series and anecdotal case reports of dementia with an onset below the age of 45 years. In this case report, we present the case of a 23 years old female that presented with psychotic features initially and on clinical examination and imaging was diagnosed as young onset frontotemporal dementia.
\end{abstract}

Keywords: Dementia, Young onset dementia, Fronto-temporal dementia.

\section{Introduction}

The diagnosis of dementia at any age is a clinical challenge and more so when it is seen in younger people below the age of 45 years. Over the recent years there has huge clinical interest with more case reports of young onset dementias emerging where the presenting symptoms are like psychosis and mental illness rather than cognitive dysfunction and memory loss. ${ }^{1}$ Most cases of frontotemporal dementia do not present with psychotic features though there are reports of young patients who have presented with schizophrenia like features but may actually have a young onset dementia process that is the cause. ${ }^{2}$ The concept of dementia preacox for schizophrenia, the neuropsychological dysfunction described in various studies and clinical features all point towards a frontotemporal theory for the psychopathology in schizophrenia. ${ }^{3}$ Recent studies in the clinical features and genetics of frontotemporal dementia have renewed interest in the psychological symptoms that may be seen in the disorder. ${ }^{4} \mathrm{We}$ present herewith the case of a 23 year old female that presented with psychotic features and on examination and revealed itself to be a young onset frontotemporal dementia.

\section{Case Report}

A 23 years old, Hindi speaking right handed Muslim married female, educated till $10^{\text {th }}$ standard and homemaker was brought to the psychiatry outpatient department by her mother with chief complaints of claiming that her house and belongings are infested by spiders and cockroaches, decreased self-care, lack of empathy, passing urine and stool in clothes all since the past 8 months. These symptoms were insidious in onset, continuous and progressive in nature since they started.

The patient was apparently alright around a year and 8 months back when her in-laws noticed a change in her behaviour following which her mother was informed. She would be seen reluctant to go to the washroom and not take a bath for days at a stretch. She however would be seen washing her hands repetitively often emptying the entire water tank in the process. On being confronted about the same, she started claiming that her house is infested with spiders and cockroaches and hence her behaviour was justified. She would demand thorough cleaning of the washroom and change of soap after which she agreed to take a bath. On being asked where the insects were seen, she would point to the ceiling, floor, racks, cupboards and even on her clothes and try to remove them with her hand. She would further be seen cleaning her children's clothes with a brush repetitively to remove the insects. Gradually the symptoms worsened, she would not do her household chores remain engrossed in the repetitive acts following which she was forced to leave for her maternal house.

In her maternal house, the symptoms persisted. The mother further noticed that there would be marked increase in her appetite, specially craving for carbohydrates and sweets. She would demand for pizza, burgers, colas, eat 6-8 eggs at one time which was not usual for her. On multiple occasions she would be seen going out of the house to nearby eateries, would ask random strangers to feed her and on occasions take food served in their plate and eat it at one go stating she was hungry. Due to her increased appetite she gained around $25-30 \mathrm{~kg}$ in 2-3 months.

Around a year back there was further deterioration of her symptoms, she would be seen passing socially inappropriate comments and jokes. On occasions she would comment on the size of her grandmother's breasts in a room full of people and try to touch them. She would be seen asking the elderly in her house to go and beg in front of a mosque as they were a burden to the family. On one occasion, during the funeral of her uncle, she started laughing and claiming what good had he done in life to deserve such a grand funeral. She would often board autorickshaws, get down without paying claiming she did not need to pay anyone. In between, the patient would be seen having crying spells, wherein she would remember her kids and curse her in laws openly praying a speedy death to them for separating her from her kids. The patient would further be seen having spells of laughter interspersed with laughter for no apparent reason.

Around 8months back the patient started passing urine in clothes. On being confronted by her mother she would 
state its not urine but water and try to make her mother smell the same. About 6months ago, she started passing stool in clothes, she would go out with soiled clothes and on being confronted pass more stools and try to smear it on the floor.She stopped doing even the basic household chores, started requiring assistance for self-care. She would further have difficulty in mentioning the date/day/time but would be able to tell whether it was day or night. She would often repeat a question again and again although she would have no difficulty in facial recognition or navigation. There was associated change in vocal tone wherein she would start speaking in a high pitch child like voice. There would not be any stuttering/stammering or having difficulty naming things however.

There was no associated abnormal movements or history of seizures. There was no history of preceding febrile illness or head trauma. There was no previous history suggestive of psychosis, depression, mania, OCD, substance use and other psychiatric disorder.

The worsening symptoms led them to try faith healing with no avail following which patient was taken to a private psychiatrist 8months after the onset of symptoms. She was diagnosed as suffering from Delusional Parasitosis andwas started on Trifluperazine $10 \mathrm{mg}$ per day in divided doses which was increased to $20 \mathrm{mg}$ /day with minimal benefit. She was taken to another psychiatrist and was started on Fluvoxamine $100 \mathrm{mg}$, Trifluoperazine $10 \mathrm{mg}$, Clonazepam $0.5 \mathrm{mg}$, Divalproate Sodium 250mg (all in divided doses through the day). The treatment continued for 6months with good compliance but minimal benefit and gradual worsening of her behaviour following which routine blood investigations were carried out along with magnetic resonance imaging (MRI) of the brain.

Her thyroid function was abnormal and she was given thyroxine supplementation was done (25ug/day before breakfast). Her MRI revealed diffuse bilateral frontal temporal atrophy seen in the form of prominence of subarachnoid spaces, sylvian fissure and ventricles, following which a diagnosis of young onset Frontotemporal Dementia was made and the patient referred to our hospital for further treatment.

The patient was the $4^{\text {th }}$ among 5 siblings. There was a history suggestive of neonatal deaths in 2 of her elder siblings due to low birth weight and death at 7 months of age of another sibling because of seizure disorder. History suggestive of psychiatric illness was present in her maternal grand uncle and maternal uncle in form of irrelevant talk, wandering away behaviour, although further details were not available.

The patient was a full-term vaginal delivery, cried immediately after birth, birth weight was $3 \mathrm{~kg}$ as per the mother and there was no history suggestive of any problems after the birth of the patient and in her developmental years. Age appropriate developmental milestones were achieved. She had studied till $10^{\text {th }}$ standard in a Hindi medium school, was average in academics and had to stop academics due to an early marriage. There was history suggestive of conduct problems, school refusal, ADHD and enuresis. Currently she had no complaints suggestive of any sequel of the above problems. She was homemaker, would engage in a range of household activities and help husband with the finances. She was married at 16years of age and had a 4 years old son. The husband remarried another woman 2 yearago as per Islam without divorcing her and predominantly favoured the second wife. The patient achieved menarche achieved at 13 years of age, and her monthly cycles were regular. Her premorbid personality was socially well adjusted

On physical examination her pulse, blood pressure and respiratory rate were normal and there were no medical signs evident. Even her systemic examination was normal. There were no tremors, rigidity or any other abnormal movements noted.

On mental status examination, the patient was seen dressed in hospital clothes, head covered with a scarf and was obese. The patient had to be requested multiple times to sit on the stool, would get up multiple times in between. She would interrupt her mother during the interview, get anxious if mother was asked to leave her side to sign documents insisting on the motherbeing with her always. She would play music in her mother's phone and laugh during the interview. She was conscious, uncooperative, communicative and rapport could not be established. Her eye to eye contact was initiated but not maintained. Her attention was arousable but ill sustained, passive attention decreased and mood was conveyed as happy. Her affect was observed to be silly, labile, reactive and inappropriate to thought and surroundings.

Her speech showed increased latency, high pitch and was childlike. She had thought derailment, delusions of infestation, tactile hallucinations related to the same and visual hallucinations of spiders and cockroaches. No auditory hallucinations were present. No other forms of delusions were mentioned. She did not cooperate for further mental status assessment and hence could not be assessed further. The patient did not cooperate for informal memory testing on MSE. Later she was unable to answer recall and retention on bedside testing after admission.Her judgement socially was impaired and insight was grade1. On bedside assessment her Mini Mental Status Examination (MMSE) score was 13/30 and her Frontal Assessment Battery (FAB) scores was 6/18. She was diagnosed as Major Frontotemporal Neurocognitive Disorder; Behavioural Variant - young onset as per DSM-5 criteria. She was started on low dose Risperidone $1 \mathrm{mg}$ twice a day, Trihexyphenydyl $2 \mathrm{mg}$ once a day, Piracetam $800 \mathrm{mg}$ twice a day and was started on Citicholine $500 \mathrm{mg}$ per day by the neurologist. She did not follow up and we have no further details on the progress of the case. Her MRI Imaging showed bilateral atrophy in the frontal and temporal regions which was not in keeping with age as per the report sent but her MRI plates were awaited.As we are not in contact with case her imaging pictures are not available for this case report. She had signed the consent forms for case report publication and was to return with her MRI plates for the photograph but did not follow up. 


\section{Discussion}

The observed relationship between schizophrenia and frontotemporal dementia may be due to shared localisation of brain pathology, i.e. the occurrence of a pathological process in the same brain regions of young adults leads to a similar clinical phenotype. ${ }^{5}$ There is also evidence for the overlap of clinical, neuropsychological and neuroimaging findings in schizophrenia and frontotemporal dementia. ${ }^{6}$ This is coupled with deficits in social cognition, theory of mind, empathy and affect recognition have been identified in both disorders. ${ }^{7}$ Our case presented more with delusions of infestation and some obsessive compulsive symptoms. It is important to note that frontal hypoperfusion on single photon emission tomography/positron emission tomography is one of the imaging criteria for the diagnosis of frontotemporal dementia, and is also one of commonest functional imaging findings in the schizophrenia (chronic and first-episode). ${ }^{8}$ It has been reported in some patients diagnosed with schizophrenia, that they may have an insidious, slowly evolving frontotemporal dementia associated with motor neuron diseaselike pathology beginning in the hippocampus and then moving on the cerebral cortex. ${ }^{9}$ Though rare, clinicians must be aware of young onset frontotemporal dementia and its diagnosis though rare may be seen in clinical practice.

\section{Acknowledgements}

Nil.

\section{Source of Funding}

None.

\section{Conflict of Interest}

None.

\section{References}

1. Rossor MN, Fox NC, Mummery CJ, Schott JM, Warren JD. The diagnosis of young-onset dementia. Lancet Neurol. 2010;9(8):793-806.

2. Kelley BJ, Boeve BF, Josephs KA. Young-onset dementia: demographic and etiologic characteristics of 235 patients. Arch Neurol. 2008;65(11):1502-8.

3. Aderibigbe YA, Theodoridis D, Vieweg WV. Dementia praecox to schizophrenia: the first 100 years. Psychiatr Clin Neurosci. 1999;53(4):437-48.

4. Neary D, Snowden J, Mann D. Frontotemporal dementia. Lancet Neurol. 2005;4(11):771-80.

5. Velakoulis D, Walterfang M, Mocellin R, Pantelis C, McLean C. Frontotemporal dementia presenting as schizophrenia-like psychosis in young people: clinicopathological series and review of cases. Br J Psychiatry. 2009;194(4):298-305.

6. Deutsch SI, Rosse RB, Lakshman RM. Dysregulation of tau phosphorylation is a hypothesized point of convergence in the pathogenesis of alzheimer's disease, frontotemporal dementia and schizophrenia with therapeutic implications. Progr Neurosychopharmacol Biol Psychiatry. 2006;30(8):1369-80.

7. Harciarek M, Malaspina D, Sun T, Goldberg E. Schizophrenia and frontotemporal dementia: Shared causation?. Int Rev Psychiatry. 2013;25(2):168-77.

8. Cooper JJ, Ovsiew F. The relationship between schizophrenia and frontotemporal dementia. J Geriatr Psychiatr Neurol. 2013;26(3):131-7.

9. Shinagawa S, Nakajima S, Plitman E, Graff-Guerrero A, Mimura M, Nakayama K, Miller BL. Psychosis in frontotemporal dementia. J Alzheim Dis. 2014;42(2):485-99.

How to cite this article: Roy $\mathrm{P}$, Chaudhari P, Pandit HM, Shah N, Karia S, De Sousa A. Young onset fronto-temporal dementia - A case report. Telangana $J$ Psychiatry. 2020;6(1):99-101. 